\title{
Cannabinoid Receptor Signaling in Central Regulation of Feeding Behavior: A Mini-Review
}

\author{
Marco Koch* \\ Medical Faculty, Institute of Anatomy, University of Leipzig, Leipzig, Germany
}

Cannabinoids are lipid messengers that modulate a variety of physiological processes and modify the generation of specific behaviors. In this regard, the cannabinoid receptor type $1\left(\mathrm{CB}_{1}\right)$ represents the most relevant target molecule of cannabinoids so far. One main function of central $\mathrm{CB}_{1}$ signaling is to maintain whole body energy homeostasis. Thus, cannabinoids functionally interact with classical neurotransmitters in neural networks that control energy metabolism and feeding behavior. The promotion of $\mathrm{CB}_{1}$ signaling can increase appetite and stimulate feeding, while blockade of $\mathrm{CB}_{1}$ suppresses hunger and induces hypophagia. However, in order to treat overeating, pharmacological blockade of $\mathrm{CB}_{1}$ by the inverse agonist rimonabant not only suppressed feeding but also resulted in psychiatric side effects. Therefore, research within the last

OPEN ACCESS

Edited by:

Hubert Vaudry,

University of Rouen, France

Reviewed by:

Daniela Cota

Institut National de la Santé et de la

Recherche Médicale, France

Denis Richard,

Laval University, Canada

*Correspondence:

Marco Koch

marco.koch@medizin.uni-leipzig.de

Specialty section:

This article was submitted to Neuroendocrine Science,

a section of the journal

Frontiers in Neuroscience

Received: 15 February 2017 Accepted: 09 May 2017 Published: 24 May 2017

Citation:

Koch M (2017) Cannabinoid Receptor Signaling in Central Regulation of Feeding Behavior: A Mini-Review.

Front. Neurosci. 11:293. doi: 10.3389/fnins.2017.00293 decade focused on deciphering the underlying cellular and molecular mechanisms of central cannabinoid signaling that control feeding and other behaviors, with the overall aim still being the identification of specific targets to develop safe pharmacological interventions for the treatment of obesity. Today, many studies unraveled the subcellular localization of $\mathrm{CB}_{1}$ and the function of cannabinoids in neurons and glial cells within circumscribed brain regions that represent integral parts of neural circuitries controlling feeding behavior. Here, these novel experimental findings will be summarized and recent advances in understanding the mechanisms of $\mathrm{CB}_{1}$-dependent cannabinoid signaling being relevant for central regulation of feeding behavior will be highlighted. Finally, presumed alternative pathways of cannabinoids that are not driven by $\mathrm{CB}_{1}$ activation but also contributing to control of feeding behavior will be introduced.

\footnotetext{
Keywords: cannabinoid receptor type 1, endocannabinoids, hypothalamus, feeding behavior, anorexia, cachexia, overeating, obesity
}

\section{INTRODUCTION}

Central regulation of feeding behavior is indispensable to life, since animals and men have to consume energy in terms of food to exert essential daily functions (Gao and Horvath, 2016). In this regard, a network of neural circuitries evolved that ensures constant energy supply by providing a "pro-feeding" behavioral outcome: in times when food is plentiful, energy intake dominates energy expenditure, so that excessive energy could be stored and used when food was restricted or temporarily not available (Koch and Horvath, 2014).

Cannabinoids, such as THC interfere with central regulation of feeding behavior by acting upon G protein-coupled cannabinoid receptor type $1\left(\mathrm{CB}_{1}\right)$ in the brain (Williams and Kirkham, 1999). 
However, the underlying molecular and cellular mechanisms of central $\mathrm{CB}_{1}$ signaling in control of feeding and other behaviors are still far from being fully understood (Mazier et al., 2015). Moreover, better insight into the aforementioned network being responsible for central control of feeding behavior is of significant interest, since nowadays, the respective neural circuitries are of substantial clinical relevance. Most importantly, availability of food no longer represents an evolutionary pressure, since food exists in abundance in many (albeit not all) countries around the world. Moreover, energy-dense foods high in carbohydrates and rich in fat can be obtained with little or no efforts. Thus, many people are suffering from chronic overload with nutrients in today's world, which, when accompanied by overall decreased physical activity is often leading to a morbid increase in body fat mass and resulting in obesity. On the other hand, a significant number of patients is affected from a complete loss of appetite (anorexia), which may be caused by psychiatric disorders, or by cancer and infectious diseases, and make these patients suffering from chronic under-nutrition (Scarlett and Marks, 2005; Park et al., 2014). Thus, decoding of the underlying cellular and molecular mechanisms in the central nervous system (CNS) that control feeding behavior may help to develop pharmacological interventions not only for disorders related with anorexia, but also for the treatment of the ever-increasing number of obese patients worldwide (Dietrich and Horvath, 2012).

Since time immemorial, cannabis extracts are used for recreational purposes. However, it is clear today that not only the psychotropic properties but also the well-known appetite stimulating effects of the plant-derived cannabinoid THC are mediated by $\mathrm{CB}_{1}$ activation (Silvestri and Di Marzo, 2013). $\mathrm{CB}_{1}$ belongs to the endocannabinoid system (ECS) that further consists of endocannabinoids (eCBs) as intrinsic $\mathrm{CB}_{1}$ ligands, and of eCB synthesizing and hydrolyzing enzymes (Piomelli, 2003). These enzymes steadily control eCB levels in a temporal and spatial fashion to guaranty functional $\mathrm{CB}_{1}$ signaling in a region and cell type specific manner (Pertwee, 2014). Interestingly, malfunction of the central ECS is associated with overeating and obesity (Engeli, 2008; Mazier et al., 2015). Thus, the main purpose here is to summarize recent experimental findings for central control of feeding behavior in health and disease, with special focus on central $\mathrm{CB}_{1}$ signaling. Finally, presumed alternative, non- $\mathrm{CB}_{1}$ driven pathways by which eCBs might also contribute to feeding regulation will be introduced.

\section{DOES CB $_{1}$ STILL LEND ITSELF AS A THERAPEUTIC TARGET IN CENTRAL FEEDING REGULATION?}

$\mathrm{CB}_{1}$ was discovered almost 30 years ago and later identified as a promising target molecule in the CNS to pharmacologically interfere with feeding behavior (Matsuda et al., 1990; Devane et al., 1992; Williams and Kirkham, 1999). Besides feeding, several other physiological functions, and behaviors being modulated by central $\mathrm{CB}_{1}$ signaling were deciphered so far (Lutz et al., 2015), and many pharmacological, biochemical, and morphological aspects of central $\mathrm{CB}_{1}$ signaling were characterized.
The vast majority of $\mathrm{CB}_{1}$ is located at presynaptic terminals in order to suppress the further release of classical neurotransmitters, such as GABA or glutamate (Castillo et al., 2012). However, different localizations and functions of $\mathrm{CB}_{1}$ were also discovered (Figure 1). In principle, the acute pharmacological promotion of central $\mathrm{CB}_{1}$ signaling can evoke food intake and thus still represents a promising approach to treat anorexia (Williams and Kirkham, 1999; Aigner et al., 2011; Reuter and Martin, 2016). However, it was discovered a couple of years ago that only administration of low to moderate doses of $\mathrm{CB}_{1}$ agonists were able to increase food intake in mice, while moderate to high doses of $\mathrm{CB}_{1}$ agonists decreased feeding (Bellocchio et al., 2010). In this, hypophagia was induced by $\mathrm{CB}_{1}$-mediated reduction of GABAergic transmission, while hyperphagia was stimulated by $\mathrm{CB}_{1}$-driven suppression of glutamatergic conduction (Bellocchio et al., 2010; Busquets Garcia et al., 2016). This fundamental finding in mice might explain the contrary results of different clinical trials on the use of $\mathrm{CB}_{1}$ agonists in order to treat anorexia in humans (Aigner et al., 2011; Reuter and Martin, 2016). Thus, further approaches are needed to carefully reconsider the beneficial effects of $\mathrm{CB}_{1}$ agonists for the treatment of anorexia (Whiting et al., 2015). In contrast to $\mathrm{CB}_{1}$ agonists, the overall blockade of $\mathrm{CB}_{1}$ by rimonabant generally suppressed hunger and induced hypophagia (Colombo et al., 1998; Simiand et al., 1998), but unfortunately also resulted in psychiatric side effects in humans. To develop more specific and safe pharmacological interventions for the treatment of overeating, the recently presented molecular ultrastructure of human $\mathrm{CB}_{1}$ may deliver new opportunities for the design of next-generation $\mathrm{CB}_{1}$ directing pharmaceuticals as novel anti-obesity drugs (Hua et al., 2016; Shao et al., 2016). Moreover, allosteric agents directed against $\mathrm{CB}_{1}$ such as hemopressin or pregnenolone (Heimann et al., 2007; Dodd et al., 2010, 2013; Vallee et al., 2014) may supply medications with a significantly improved side effect profile (Busquets Garcia et al., 2016). Finally, another pharmacological approach aimed at selective blockade of peripheral $\mathrm{CB}_{1}$, which basically was shown to induce metabolic benefits independently from modification of feeding behavior (Nogueiras et al., 2008; Tam et al., 2012). Nevertheless, it is primarily the knowledge about the cell type specific functions of $\mathrm{CB}_{1}$ signaling in different types of neurons, and, as discussed later, also in glial cells, such as astrocytes (Metna-Laurent and Marsicano, 2015), which will determine if and in how far the full therapeutic potential of $\mathrm{CB}_{1}$ pharmacology in feeding regulation can be leveraged.

In this regard, complexity of central $\mathrm{CB}_{1}$ signaling was further broaden by the observation that $\mathrm{CB}_{1}$, as a $\mathrm{G}$ proteincoupled receptor, is not exclusively expressed at the plasma membrane but also located at the outer mitochondrial membrane (Benard et al., 2012; Hebert-Chatelain et al., 2014). By interfering with respiratory chain complex $\mathrm{I}$, mitochondrial $\mathrm{CB}_{1}$ was recently shown to promote the amnesia-inducing effects of $\mathrm{CB}_{1}$ agonists in the hippocampus (Hebert-Chatelain et al., 2016; Harkany and Horvath, 2017). Accordingly, effects of cannabinoids on food intake are also transmitted via $\mathrm{CB}_{1}$ induced mitochondrial adaptations, since induction of feeding by $\mathrm{CB}_{1}$ agonists depended on the expression of mitochondrial uncoupling protein 2 and the formation of reactive oxygen 


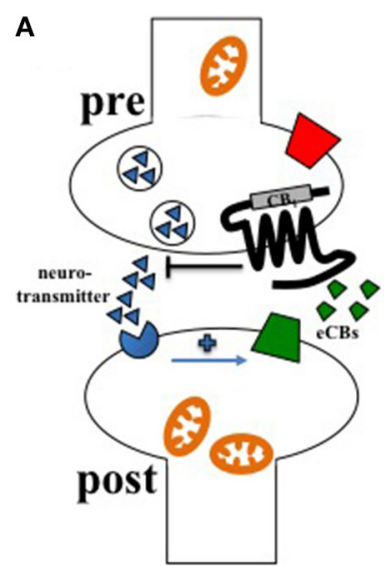

B

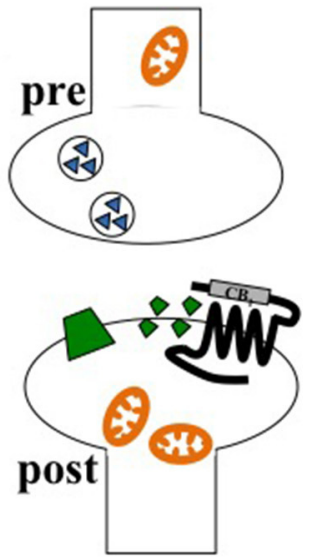

D

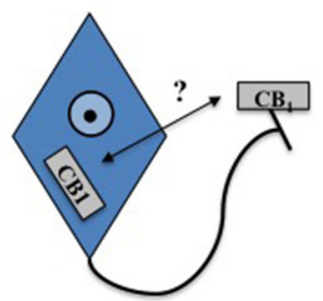

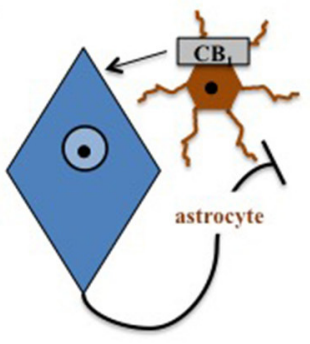

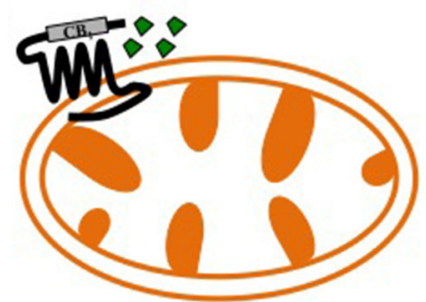

mitochondrial $\mathrm{CB}_{1}$

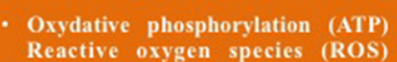

Uncoupling protein 2

$\mathbf{F}$

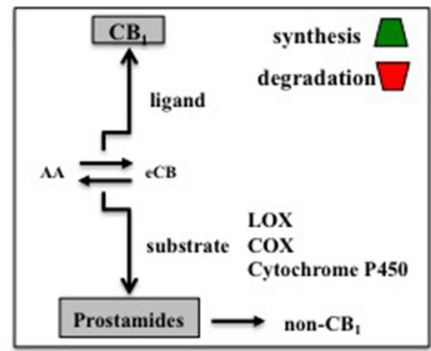

FIGURE 1 | Principles of central $\mathrm{CB}_{1}$ signaling in control of feeding behavior. (A) Retrograde signaling of eCBs at presynaptic $\mathrm{CB}_{1}$ impacts feeding (Bellocchio et al., 2010). (B) Postsynaptic $\mathrm{CB}_{1}$ at POMC neurons affects feeding in DIO (Morello et al., 2016). (C) Cannabinoids interfere with mitochondrial $\mathrm{CB}_{1}$ in hypothalamic

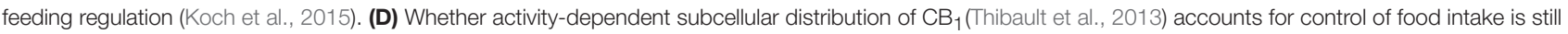
open. (E) Astroglial $\mathrm{CB}_{1}$ regulates the metabolic effects of leptin in cultured astrocytes (Bosier et al., 2013), and thus might contribute to astrocyte-dependent control of feeding behavior in the hypothalamus (Kim et al., 2014). (F) Enzymes of eCB synthesis or degradation control eCB levels in a spatial and temporal manner (Pertwee, 2014). Moreover, eCBs not only function as $\mathrm{CB}_{1}$ ligands, but also as substrates of specific enzymes, such as lipoxygenases (LOX), cyclooxygenases (COX), or cytochrome $\mathrm{P} 450$, supporting the idea that the ECS might also transmit metabolic effects independently from $\mathrm{CB}_{1}$ signaling (non-CB 1 ).

species (ROS) in the hypothalamus (Koch et al., 2015; Kruger, 2016), finally pointing toward region-specific functions of mitochondrial $\mathrm{CB}_{1}$ signaling in the brain (Harkany and Horvath, 2017). However, $\mathrm{CB}_{1}$ driven control of ROS seems to be multifaceted, since cannabinoids reduced leptin-mediated ROS formation in cultured hypothalamic neurons by $\mathrm{CB}_{1}$ dependent peroxisome proliferator-activated receptors (PPAR)gamma and subsequent catalase activation (Palomba et al., 2015). Overall, about $15 \%$ of total brain $\mathrm{CB}_{1}$ is associated with mitochondria (Benard et al., 2012; Hebert-Chatelain et al., 2014), and it appeared that $\mathrm{CB}_{1}$ is present in mitochondria of both pre- and postsynaptic terminals (Busquets Garcia et al., 2016). However, $\mathrm{CB}_{1}$ is most abundantly expressed at the plasma membrane of axonal shafts and presynaptic terminals (Pertwee, 2010), and significant amounts of $\mathrm{CB}_{1}$ in the forebrain are constantly activated, internalized, and recycled at steady state (Thibault et al., 2013). Whether internalization and redistribution of $\mathrm{CB}_{1}$ between axonal plasma membrane and somato-dendritic endosomes account for control of feeding behavior still needs to be investigated. Moreover, functional expression of $\mathrm{CB}_{1}$ is also observed at the postsynaptic plasma membrane (Castillo et al., 2012). In the course of diet-induced obesity (DIO), orexin-A represses satiety-promoting pro-opiomelanocortin (POMC) neurons in the hypothalamic arcuate nucleus (ARC) by eCB-mediated activation of postsynaptic $\mathrm{CB}_{1}$ on POMC neurons (Morello et al., 2016).

In addition to neurons, $\mathrm{CB}_{1}$ is also expressed in astrocytes (Metna-Laurent and Marsicano, 2015; Oliveira Da Cruz et al., 2016), and plays an important role in neuroinflammation (Walter and Stella, 2004), and in physiological neurotransmission (Navarrete and Araque, 2010; Han et al., 2012). Interestingly, astrocyte-dependent energetic support of neurons also involves $\mathrm{CB}_{1}$, since leptin-induced astroglial glycogen accumulation depends on $\mathrm{CB}_{1}$ signaling in cultured astrocytes (Bosier et al., 2013). However, the relevance of astroglial $\mathrm{CB}_{1}$ in distinct hypothalamic feeding centers has to be considered in vivo. Accordingly, structural analyses determined $\mathrm{CB}_{1}$ in the immediate vicinity to astrocytes at tripartite synapses in the ARC (Morozov et al., 2017). Moreover, hypothalamic astrocytes and microglia show morphological adaptations in DIO (Baufeld et al., 2016; Argente-Arizon et al., 2017), and astrocytes, via leptin signaling, actively control hypothalamic neuronal circuits, and feeding (Kim et al., 2014). Thus, it is of significant interest to study the function of $\mathrm{CB}_{1}$ signaling in glial cells under normal and high fat diet (HFD). 
Together, studies focusing on the cell type specific expression and subcellular distribution of $\mathrm{CB}_{1}$ delivered unique mechanistic insights into central $\mathrm{CB}_{1}$ signaling, which provides an important prerequisite to uncover the physiological role of $\mathrm{CB}_{1}$ in distinct homeostatic and hedonic feeding centers of the CNS.

\section{RECENT ADVANCES IN UNDERSTANDING HOMEOSTATIC AND HEDONIC FEEDING CONTROL: WHAT IS THE RELEVANCE OF $\mathrm{CB}_{1}$ ?}

Homeostatic feeding centers supervise the body's energy resources and are located in the hypothalamus and caudal brainstem (Koch and Horvath, 2014), while hedonic feeding centers relevant for palatability and rewarding aspects of food are pinpointed to the mesolimbic system (Alonso-Alonso et al., 2015; Pandurangan and Hwang, 2015). Although both control systems are anatomically located in different brain areas, it becomes more likely that they are functionally closely interconnected to each other (Munzberg et al., 2016).

$\mathrm{CB}_{1}$ obtains a conserved distribution in the CNS among different mammalian species (Herkenham et al., 1990). High $\mathrm{CB}_{1}$ expression levels in the hippocampus or basal ganglia are attributed to cannabinoid-induced effects on memory formation and movement (Castillo et al., 2012). Low $\mathrm{CB}_{1}$ expression levels in hypothalamic or caudal brainstem nuclei display significant functions in regulation of feeding behavior (Cardinal et al., 2012; Mazier et al., 2015). In this, distinct groups of hypothalamic neurons measure the body's energy resources by sensing circulating nutrients and detecting metabolic hormones, such as leptin, insulin, or ghrelin (Varela and Horvath, 2012; Vogt and Bruning, 2013; Muller et al., 2015). Moreover, hypothalamic neurons are directly affected by cannabinoids, since infusion of $\mathrm{CB}_{1}$ agonists into distinct hypothalamic nuclei acutely induced feeding (Jamshidi and Taylor, 2001; Koch et al., 2015). Interestingly, hypothalamic $\mathrm{CB}_{1}$ signaling interferes with signal transmission of metabolic hormones. While leptin suppressed feeding correlates with decreased hypothalamic eCB levels (Di Marzo et al., 2001), ghrelin triggered acute feeding accompanies with increased hypothalamic eCB levels, and depends on paraventricular nucleus (PVN) $\mathrm{CB}_{1}$ signaling (Kola et al., 2008). However, $\mathrm{CB}_{1}$ mediated control of feeding in the PVN is more complex than thought before, since under an experimental fasting/re-feeding paradigm, blockade of local $\mathrm{CB}_{1}$ in the PVN increased hyperphagy in hungry mice, and enhanced the hyperphagic effect of ghrelin in fed animals (Soria-Gomez et al., 2014b). Thus, hypothalamic eCBs represent local neuromodulators that are actively involved in rapid rewiring of hypothalamic feeding circuits in accordance to the current prandial state (Pinto et al., 2004). In DIO, imbalanced hypothalamic eCB levels and defective $\mathrm{CB}_{1}$ signaling seem to be the consequence of central leptin resistance (Silvestri and Di Marzo, 2013). In the lateral hypothalamus $(\mathrm{LH}), \mathrm{CB}_{1}$ is involved in physiological control of melanin-concentrating hormone and orexin-A neurons (Silvestri and Di Marzo, 2013). In DIO, eCBs in the $\mathrm{LH}$ promote hyperphagia by remodeling the synaptic input organization of orexin-A neurons (Alpar and Harkany, 2013; Cristino et al., 2013).

In the ARC, at least two neuronal populations with opposing effects on feeding behavior can be distinguished: the hunger promoting Agouti-related protein/neuropeptide Y (AgRP/NPY) neurons that acutely promote food intake, and POMC neurons that drive gradual onset of satiety (Varela and Horvath, 2012). Systemic blockade of $\mathrm{CB}_{1}$ by rimonabant reduced NPY levels, indicating that AgRP/NPY neurons are controlled by local eCBs (Verty et al., 2009). AgRP/NPY neurons do not contain $\mathrm{CB}_{1}$ (Cota et al., 2003; Horvath, 2003), but $\mathrm{CB}_{1}$ was predominately found at GABAergic terminals innervating AgRP/NPY neurons (Morozov et al., 2017). Thus, local eCBs in the ARC might promote feeding by retrograde dis-inhibition of AgRP/NPY neurons. However, POMC neurons are also affected by cannabinoids via pre- and postsynaptic $\mathrm{CB}_{1}$ (Hentges et al., 2005; Koch et al., 2015; Morello et al., 2016). In fed mice, $\mathrm{CB}_{1}$ agonists rapidly converted POMC neurons from promoters of long-term satiety into acute drivers of hunger (Koch et al., 2015; Patel and Cone, 2015). In DIO, orexin-A repressed POMC neurons by constitutive eCB signaling at postsynaptic $\mathrm{CB}_{1}$ in POMC neurons (Morello et al., 2016). Mapping of hypothalamic neuronal subtypes by single-cell RNA sequencing (Romanov et al., 2017) and molecular indexing of local ARC cell types by gene expression profiling identified novel cell types of putative relevance for regulation of distinct vegetative body functions, including feeding (Campbell et al., 2017). Thus, it would be interesting to dissect the functional relevance of $\mathrm{CB}_{1}$ signaling in these cell types. Accordingly, glutamate-releasing neurons in the ARC that express oxytocin receptors were identified as an integral part of a rapid ARC to PVN satiety pathway (Fenselau et al., 2017). However, whether acute effects of cannabinoids on feeding might be further transmitted by this novel pathway remains elusive. Alongside, local ARC dopaminergic cells were identified that reciprocally control activity of AgRP/NPY and POMC neurons (Zhang and Van Den Pol, 2016). This finding is of substantial interest in order to study $\mathrm{CB}_{1}$ controlled homeostatic feeding, since dopamine modulates rewarding aspects of food mainly through dopaminergic ventral tegmental area (VTA) to nucleus accumbens (NAc) projections (Volkow et al., 2011), and $\mathrm{CB}_{1}$ signaling was shown to modulate dopaminergic signaling in the NAc and VTA to regulate hedonic aspects of feeding (Melis et al., 2007; Di Marzo et al., 2009).

Beside the VTA located in the rostral brainstem, $\mathrm{CB}_{1}$ signaling is also interfering with the functional activity of caudal brainstem nuclei, such as parabrachial nucleus, dorsal motor nucleus of the vagus, and nucleus of the solitary tract. In this, $\mathrm{CB}_{1}$ basically controls food preferences, such as digestion of palatable foods being rich in fat (Busquets Garcia et al., 2016). Finally, hypothalamic AgRP/NPY and POMC neurons are not only directly affected by food intake itself, but also rapidly respond to sensory detection of available food (Chen et al., 2015). It is thus likely that hypothalamic neurons not only transmit internal signals causing hunger or satiety in response to eating and internal sensing of energy resources, but also receive external information on the incentive value of food, 
such as sight, smell, and taste in order to rapidly react to food stimuli and transmit motivational aspects on feeding being generated via the mesolimbic system (Seeley and Berridge, 2015). Processing of food sensations such as olfactory or gustatory signals indeed involve $\mathrm{CB}_{1}$ signaling, since fasted mice displayed $\mathrm{CB}_{1}$-dependent increased odor detection in the main olfactory bulb (Soria-Gomez et al., 2014a).

\section{BESIDES CB $_{1}$ : DOES THE ECS PROVIDE OTHER RELEVANT TARGET MOLECULES IN FEEDING REGULATION?}

Within the ECS, it is the availability of eCBs that provides the routes and directions of $\mathrm{CB}_{1}$ signaling in the brain. While research was long-time focusing on pharmacological modulation of $\mathrm{CB}_{1}$ signaling by direct interaction at $\mathrm{CB}_{1}$ in order to interfere with feeding and other behaviors, numerous evidence arose that targeting of classical enzymes involved in biosynthesis or degradation of eCBs will also allow to induce adaptations in feeding behaviors (Pertwee, 2014). For example, degradation of the eCB 2-arachidonoylglycerol (2-AG) into arachidonic acid and glycerol is basically controlled by three different serine hydrolases: while monoacylglycerol lipase (MAGL) accounts for $85 \%$ of $2-A G$ degradation, alpha/beta-hydrolase domain containing (ABHD) 6, and 12 are responsible for hydrolysis of 5 and 10\%, respectively (Savinainen et al., 2012). Indeed, it was shown that knockdown of ABHD6 in the ventromedial hypothalamus resulted in locally elevated 2-AG levels, finally resulting in a blunted fasting-induced feeding response and in a general diminished efficacy of the mice in order to adapt to other metabolic shifts (Fisette et al., 2016).

Generally, eCBs do not resemble to classical neurotransmitters that are stored in synaptic vesicles (Piomelli, 2003). Instead, eCBs, as being arachidonic acid derivatives, are produced on demand from lipid precursors. Most eCBs display a relative short halflife, since they are attracted by both classical eCB degrading enzymes in order to terminate $\mathrm{CB}_{1}$ signaling, and by different classes of enzymes aiming transformation of eCBs into other classes of lipidergic signaling molecules, such as prostamides (Urquhart et al., 2015). The fact that eCBs belong to the family of polyunsaturated fatty acids makes them indeed attractive substrates for enzymatic oxidation, as induced by lipoxygenases (LOX), cyclooxygenases (COX), or cytochrome P450 (Rouzer and Marnett, 2011). Numerous eCBs have been described so far and in addition to $2-\mathrm{AG}$ it is arachidonoylethanolamine (AEA) representing by far the best-studied intrinsic ligand of $\mathrm{CB}_{1}$ today. However, beside $\mathrm{CB}_{1}$ and $\mathrm{CB}_{2}$ as the most relevant $\mathrm{G}$ proteincoupled receptors of cannabinoids, it is likely that eCBs also act upon several other G protein-coupled receptors, such as GPR18, GPR55, and GPR119. These former orphan receptors are putative

\section{REFERENCES}

Aigner, M., Treasure, J., Kaye, W., Kasper, S., and Disorders, W.T.F.O.E. (2011). World Federation of Societies of Biological Psychiatry (WFSBP) guidelines for the pharmacological treatment of eating disorders. candidates for nomination of $\mathrm{CB}_{3}$, however their relevance in feeding regulation has to be further investigated. Nevertheless, it appeared that GPR18 and GPR55 signaling is involved in processes of metabolic dysfunction (Liu et al., 2015; Rajaraman et al., 2016). Besides $G$ protein-coupled receptors, eCBs such as AEA were also shown to act upon other types of receptors, such as transient receptor potential (TRP) vanilloid 1 (Pertwee, 2010). Moreover, several enzymes involved in eCB biosynthesis, such as the AEA synthesizing $\mathrm{N}$-acyl phosphatidylethanolamine-specific phospholipase D (NAPE-PLD) not only give rise to the $\mathrm{CB}_{1}$ ligand AEA, but also to structural very similar lipid messengers that do not bind and activate $\mathrm{CB}_{1}$. In this, it was shown that oleoylethanolamine (OEA) and palmitoylethanolamine (PEA), as close related lipids of AEA, bind to PPARs (Fu et al., 2003; Lo Verme et al., 2005; Gaetani et al., 2010), which are well-known to contribute in control of glucose, lipid, and energy metabolism (Grygiel-Gorniak, 2014). Thus, the overall metabolic role of the enzymes in the ECS, beside $\mathrm{CB}_{1}$, may deliver future targets for therapeutic interventions in control of feeding behavior. Indeed, targeted lipidomics of different brain regions derived from mice either deficient for $\mathrm{CB}_{1}$, the AEA degrading enzyme FAAH or the aforementioned 2-AG degrading MAGL revealed that AEA and 2-AG hydrolyzing enzymes, when compared to $\mathrm{CB}_{1}$, link the ECS to a broader lipid signaling network in contrasting ways, which again may open an avenue in altering neurotransmission and behaviors independently of $\mathrm{CB}_{1}$ signaling (Leishman et al., 2016a). This assumption is further supported by another lipidomic analysis. In this, mice deficient for NAPE-PLD not only displayed a shift in the concentration of AEA, but also shifted several other lipids, not binding to $\mathrm{CB}_{1}$, such as OEA and PEA, that as mentioned before signal upon different metabolic relevant targets, such as PPARs (Leishman et al., 2016b).

\section{OUTLOOK}

Actually, there has been significant increase of knowledge about central $\mathrm{CB}_{1}$ signaling in control of feeding behavior. Despite the significant setback that occurred in the past on clinical use of $\mathrm{CB}_{1}$ inverse agonists in order to treat overeating, there still is strong confidence in the field that the recent discoveries on central $\mathrm{CB}_{1}$ signaling soon will leverage the therapeutic potential of $\mathrm{CB}_{1}$.

\section{AUTHOR CONTRIBUTIONS}

MK designed this review, including Figure 1.

\section{FUNDING}

This work was supported by the Deutsche Forschungsgemeinschaft CRC 1052/2 (Obesity Mechanisms).

World J. Biol. Psychiatry 12, 400-443. doi: 10.3109/15622975.2011. 602720

Alonso-Alonso, M., Woods, S. C., Pelchat, M., Grigson, P. S., Stice, E., Farooqi, S., et al. (2015). Food reward system: current perspectives and future research needs. Nutr. Rev. 73, 296-307. doi: 10.1093/nutrit/nuv002 
Alpar, A., and Harkany, T. (2013). Orexin neurons use endocannabinoids to break obesity-induced inhibition. Proc. Natl. Acad. Sci. U.S.A. 110, 9625-9626. doi: $10.1073 /$ pnas. 1307389110

Argente-Arizon, P., Guerra-Cantera, S., Garcia-Segura, L. M., Argente, J., and Chowen, J. A. (2017). Glial cells and energy balance. J. Mol. Endocrinol. 58, R59-R71. doi: 10.1530/JME-16-0182

Baufeld, C., Osterloh, A., Prokop, S., Miller, K. R., and Heppner, F. L. (2016). Highfat diet-induced brain region-specific phenotypic spectrum of CNS resident microglia. Acta Neuropathol. 132, 361-375. doi: 10.1007/s00401-016-1595-4

Bellocchio, L., Lafenetre, P., Cannich, A., Cota, D., Puente, N., Grandes, P., et al. (2010). Bimodal control of stimulated food intake by the endocannabinoid system. Nat. Neurosci. 13, 281-283. doi: 10.1038/nn.2494

Benard, G., Massa, F., Puente, N., Lourenco, J., Bellocchio, L., Soria-Gomez, E., et al. (2012). Mitochondrial $\mathrm{CB}(1)$ receptors regulate neuronal energy metabolism. Nat. Neurosci. 15, 558-564. doi: 10.1038/nn.3053

Bosier, B., Bellocchio, L., Metna-Laurent, M., Soria-Gomez, E., Matias, I., Hebert-Chatelain, E., et al. (2013). Astroglial CB1 cannabinoid receptors regulate leptin signaling in mouse brain astrocytes. Mol. Metab. 2, 393-404. doi: 10.1016/j.molmet.2013.08.001

Busquets Garcia, A., Soria-Gomez, E., Bellocchio, L., and Marsicano, G. (2016). Cannabinoid receptor type-1: breaking the dogmas. F1000Res 2016:5. doi: 10.12688/f1000research.8245.1

Campbell, J. N., Macosko, E. Z., Fenselau, H., Pers, T. H., Lyubetskaya, A., Tenen, D., et al. (2017). A molecular census of arcuate hypothalamus and median eminence cell types. Nat. Neurosci. 20, 484-496. doi: 10.1038/nn.4495

Cardinal, P., Bellocchio, L., Clark, S., Cannich, A., Klugmann, M., Lutz, B., et al. (2012). Hypothalamic CB1 cannabinoid receptors regulate energy balance in mice. Endocrinology 153, 4136-4143. doi: 10.1210/en.2012-1405

Castillo, P. E., Younts, T. J., Chavez, A. E., and Hashimotodani, Y. (2012). Endocannabinoid signaling and synaptic function. Neuron 76, 70-81. doi: 10.1016/j.neuron.2012.09.020

Chen, Y., Lin, Y. C., Kuo, T. W., and Knight, Z. A. (2015). Sensory detection of food rapidly modulates arcuate feeding circuits. Cell 160, 829-841. doi: 10.1016/j.cell.2015.01.033

Colombo, G., Agabio, R., Diaz, G., Lobina, C., Reali, R., and Gessa, G. L. (1998). Appetite suppression and weight loss after the cannabinoid antagonist SR 141716. Life Sci. 63, PL113-PL117. doi: 10.1016/S0024-3205(98)00322-1

Cota, D., Marsicano, G., Tschop, M., Grubler, Y., Flachskamm, C., Schubert, M., et al. (2003). The endogenous cannabinoid system affects energy balance via central orexigenic drive and peripheral lipogenesis. J. Clin. Invest. 112, 423-431. doi: $10.1172 /$ JCI17725

Cristino, L., Busetto, G., Imperatore, R., Ferrandino, I., Palomba, L., Silvestri, C., et al. (2013). Obesity-driven synaptic remodeling affects endocannabinoid control of orexinergic neurons. Proc. Natl. Acad. Sci. U.S.A. 110, E2229-E2238. doi: $10.1073 /$ pnas. 1219485110

Devane, W. A., Hanus, L., Breuer, A., Pertwee, R. G., Stevenson, L. A., Griffin, G., et al. (1992). Isolation and structure of a brain constituent that binds to the cannabinoid receptor. Science 258, 1946-1949. doi: 10.1126/science.1470919

Di Marzo, V., Goparaju, S. K., Wang, L., Liu, J., Batkai, S., Jarai, Z., et al. (2001). Leptin-regulated endocannabinoids are involved in maintaining food intake. Nature 410, 822-825. doi: 10.1038/35071088

Di Marzo, V., Ligresti, A., and Cristino, L. (2009). The endocannabinoid system as a link between homoeostatic and hedonic pathways involved in energy balance regulation. Int. J. Obes. 33(Suppl. 2), S18-S24. doi: 10.1038/ijo.2009.67

Dietrich, M. O., and Horvath, T. L. (2012). Limitations in anti-obesity drug development: the critical role of hunger-promoting neurons. Nat. Rev. Drug Discov. 11, 675-691. doi: 10.1038/nrd3739

Dodd, G. T., Mancini, G., Lutz, B., and Luckman, S. M. (2010). The peptide hemopressin acts through $\mathrm{CB} 1$ cannabinoid receptors to reduce food intake in rats and mice. J. Neurosci. 30, 7369-7376. doi: 10.1523/JNEUROSCI.5455-09.2010

Dodd, G. T., Worth, A. A., Hodkinson, D. J., Srivastava, R. K., Lutz, B., Williams, S. R., et al. (2013). Central functional response to the novel peptide cannabinoid, hemopressin. Neuropharmacology 71, 27-36. doi: 10.1016/j.neuropharm.2013.03.007

Engeli, S. (2008). Dysregulation of the endocannabinoid system in obesity. $J$. Neuroendocrinol. 20(Suppl. 1), 110-115. doi: 10.1111/j.1365-2826.2008.01683.x
Fenselau, H., Campbell, J. N., Verstegen, A. M., Madara, J. C., Xu, J., Shah, B. P., et al. (2017). A rapidly acting glutamatergic ARC->PVH satiety circuit postsynaptically regulated by alpha-MSH. Nat. Neurosci. 20, 42-51. doi: 10.1038/nn.4442

Fisette, A., Tobin, S., Decarie-Spain, L., Bouyakdan, K., Peyot, M. L., Madiraju, S. R., et al. (2016). Alpha/beta-hydrolase domain 6 in the ventromedial hypothalamus controls energy metabolism flexibility. Cell Rep. 17, 1217-1226. doi: 10.1016/j.celrep.2016.10.004

Fu, J., Gaetani, S., Oveisi, F., Lo Verme, J., Serrano, A., Rodriguez De Fonseca, F., et al. (2003). Oleylethanolamide regulates feeding and body weight through activation of the nuclear receptor PPAR-alpha. Nature 425, 90-93. doi: $10.1038 /$ nature01921

Gaetani, S., Fu, J., Cassano, T., Dipasquale, P., Romano, A., Righetti, L., et al. (2010). The fat-induced satiety factor oleoylethanolamide suppresses feeding through central release of oxytocin. J. Neurosci. 30, 8096-8101. doi: 10.1523/JNEUROSCI.0036-10.2010

Gao, X. B., and Horvath, T. L. (2016). Feeding behavior: hypocretin/orexin neurons act between food seeking and eating. Curr. Biol. 26, R845-R847. doi: 10.1016/j.cub.2016.07.069

Grygiel-Gorniak, B. (2014). Peroxisome proliferator-activated receptors and their ligands: nutritional and clinical implications-a review. Nutr. J. 13:17. doi: $10.1186 / 1475-2891-13-17$

Han, J., Kesner, P., Metna-Laurent, M., Duan, T., Xu, L., Georges, F., et al. (2012). Acute cannabinoids impair working memory through astroglial CB1 receptor modulation of hippocampal LTD. Cell 148, 1039-1050. doi: $10.1016 /$ j.cell.2012.01.037

Harkany, T., and Horvath, T. L. (2017). (S)Pot on mitochondria: cannabinoids disrupt cellular respiration to limit neuronal activity. Cell Metab. 25, 8-10. doi: 10.1016/j.cmet.2016.12.020

Hebert-Chatelain, E., Desprez, T., Serrat, R., Bellocchio, L., Soria-Gomez, E., Busquets-Garcia, A., et al. (2016). A cannabinoid link between mitochondria and memory. Nature 539, 555-559. doi: 10.1038/nature20127

Hebert-Chatelain, E., Reguero, L., Puente, N., Lutz, B., Chaouloff, F., Rossignol, R., et al. (2014). Cannabinoid control of brain bioenergetics: exploring the subcellular localization of the CB1 receptor. Mol. Metab. 3, 495-504. doi: 10.1016/j.molmet.2014.03.007

Heimann, A. S., Gomes, I., Dale, C. S., Pagano, R. L., Gupta, A., De Souza, L. L., et al. (2007). Hemopressin is an inverse agonist of CB1 cannabinoid receptors. Proc. Natl. Acad. Sci. U.S.A. 104, 20588-20593. doi: 10.1073/pnas.0706980105

Hentges, S. T., Low, M. J., and Williams, J. T. (2005). Differential regulation of synaptic inputs by constitutively released endocannabinoids and exogenous cannabinoids. J. Neurosci. 25, 9746-9751. doi: 10.1523/JNEUROSCI.2769-05.2005

Herkenham, M., Lynn, A. B., Little, M. D., Johnson, M. R., Melvin, L. S., De Costa, B. R., et al. (1990). Cannabinoid receptor localization in brain. Proc. Natl. Acad. Sci. U.S.A. 87, 1932-1936. doi: 10.1073/pnas.87.5.1932

Horvath, T. L. (2003). Endocannabinoids and the regulation of body fat: the smoke is clearing. J. Clin. Invest. 112, 323-326. doi: 10.1172/JCI19376

Hua, T., Vemuri, K., Pu, M., Qu, L., Han, G. W., Wu, Y., et al. (2016). Crystal structure of the human cannabinoid receptor CB1. Cell 167, 750 e714-762 e714. doi: $10.1016 /$ j.cell.2016.10.004

Jamshidi, N., and Taylor, D. A. (2001). Anandamide administration into the ventromedial hypothalamus stimulates appetite in rats. Br. J. Pharmacol. 134, 1151-1154. doi: 10.1038/sj.bjp.0704379

Kim, J. G., Suyama, S., Koch, M., Jin, S., Argente-Arizon, P., Argente, J., et al. (2014). Leptin signaling in astrocytes regulates hypothalamic neuronal circuits and feeding. Nat. Neurosci. 17, 908-910. doi: 10.1038/nn.3725

Koch, M., and Horvath, T. L. (2014). Molecular and cellular regulation of hypothalamic melanocortin neurons controlling food intake and energy metabolism. Mol. Psychiatry 19, 752-761. doi: 10.1038/mp.2014.30

Koch, M., Varela, L., Kim, J. G., Kim, J. D., Hernandez-Nuno, F., Simonds, S. E., et al. (2015). Hypothalamic POMC neurons promote cannabinoid-induced feeding. Nature 519, 45-50. doi: 10.1038/nature14260

Kola, B., Farkas, I., Christ-Crain, M., Wittmann, G., Lolli, F., Amin, F., et al. (2008). The orexigenic effect of ghrelin is mediated through central activation of the endogenous cannabinoid system. PLoS ONE 3:e1797. doi: 10.1371 /journal.pone.0001797 
Kruger, R. P. (2016). Harvesting benefits from cannabinoids. Cell 167, 1663-1665. doi: 10.1016/j.cell.2016.12.001

Leishman, E., Cornett, B., Spork, K., Straiker, A., Mackie, K., and Bradshaw, H. B. (2016a). Broad impact of deleting endogenous cannabinoid hydrolyzing enzymes and the CB1 cannabinoid receptor on the endogenous cannabinoidrelated lipidome in eight regions of the mouse brain. Pharmacol. Res. 110, 159-172. doi: 10.1016/j.phrs.2016.04.020

Leishman, E., Mackie, K., Luquet, S., and Bradshaw, H. B. (2016b). Lipidomics profile of a NAPE-PLD KO mouse provides evidence of a broader role of this enzyme in lipid metabolism in the brain. Biochim. Biophys. Acta 1861, 491-500. doi: 10.1016/j.bbalip.2016.03.003

Liu, B., Song, S., Jones, P. M., and Persaud, S. J. (2015). GPR55: from orphan to metabolic regulator? Pharmacol. Ther. 145, 35-42. doi: 10.1016/j.pharmthera.2014.06.007

Lo Verme, J., Fu, J., Astarita, G., La Rana, G., Russo, R., Calignano, A., et al. (2005). The nuclear receptor peroxisome proliferator-activated receptoralpha mediates the anti-inflammatory actions of palmitoylethanolamide. Mol. Pharmacol. 67, 15-19. doi: 10.1124/mol.104.006353

Lutz, B., Marsicano, G., Maldonado, R., and Hillard, C. J. (2015). The endocannabinoid system in guarding against fear, anxiety and stress. Nat. Rev. Neurosci. 16, 705-718. doi: 10.1038/nrn4036

Matsuda, L. A., Lolait, S. J., Brownstein, M. J., Young, A. C., and Bonner, T. I. (1990). Structure of a cannabinoid receptor and functional expression of the cloned cDNA. Nature 346, 561-564. doi: 10.1038/346561a0

Mazier, W., Saucisse, N., Gatta-Cherifi, B., and Cota, D. (2015). The endocannabinoid system: pivotal orchestrator of obesity and metabolic disease. Trends Endocrinol. Metab. 26, 524-537. doi: 10.1016/j.tem.2015.07.007

Melis, T., Succu, S., Sanna, F., Boi, A., Argiolas, A., and Melis, M. R. (2007). The cannabinoid antagonist SR 141716A (Rimonabant) reduces the increase of extra-cellular dopamine release in the rat nucleus accumbens induced by a novel high palatable food. Neurosci. Lett. 419, 231-235. doi: 10.1016/j.neulet.2007.04.012

Metna-Laurent, M., and Marsicano, G. (2015). Rising stars: modulation of brain functions by astroglial type-1 cannabinoid receptors. Glia 63, 353-364. doi: $10.1002 /$ glia.22773

Morello, G., Imperatore, R., Palomba, L., Finelli, C., Labruna, G., Pasanisi, F., et al. (2016). Orexin-A represses satiety-inducing POMC neurons and contributes to obesity via stimulation of endocannabinoid signaling. Proc. Natl. Acad. Sci. U.S.A. 113, 4759-4764. doi: 10.1073/pnas.1521304113

Morozov, Y. M., Koch, M., Rakic, P., and Horvath, T. L. (2017). Cannabinoid type 1 receptor-containing axons innervate NPY/AgRP neurons in the mouse arcuate nucleus. Mol. Metab. 6, 374-381. doi: 10.1016/j.molmet.2017.01.004

Muller, T. D., Nogueiras, R., Andermann, M. L., Andrews, Z. B., Anker, S. D., Argente, J., et al. (2015). Ghrelin. Mol. Metab. 4, 437-460. doi: 10.1016/j.molmet.2015.03.005

Munzberg, H., Qualls-Creekmore, E., Yu, S., Morrison, C. D., and Berthoud, H. R. (2016). Hedonics act in unison with the homeostatic system to unconsciously control body weight. Front Nutr 3:6. doi: 10.3389/fnut.2016.00006

Navarrete, M., and Araque, A. (2010). Endocannabinoids potentiate synaptic transmission through stimulation of astrocytes. Neuron 68, 113-126. doi: 10.1016/j.neuron.2010.08.043

Nogueiras, R., Veyrat-Durebex, C., Suchanek, P. M., Klein, M., Tschop, J., Caldwell, C., et al. (2008). Peripheral, but not central, CB1 antagonism provides food intake-independent metabolic benefits in diet-induced obese rats. Diabetes 57, 2977-2991. doi: 10.2337/db08-0161

Oliveira Da Cruz, J. F., Robin, L. M., Drago, F., Marsicano, G., and Metna-Laurent, M. (2016). Astroglial type-1 cannabinoid receptor (CB1): a new player in the tripartite synapse. Neuroscience 323, 35-42. doi: 10.1016/j.neuroscience.2015.05.002

Palomba, L., Silvestri, C., Imperatore, R., Morello, G., Piscitelli, F., Martella, A., et al. (2015). Negative regulation of leptin-induced Reactive Oxygen Species (ROS) formation by cannabinoid CB1 receptor activation in hypothalamic neurons. J. Biol. Chem. 290, 13669-13677. doi: 10.1074/jbc.M115. 646885

Pandurangan, M., and Hwang, I. (2015). Systemic mechanism of taste, flavour and palatability in brain. Appl. Biochem. Biotechnol. 175, 3133-3147. doi: 10.1007/s12010-015-1488-3
Park, R. J., Godier, L. R., and Cowdrey, F. A. (2014). Hungry for reward: how can neuroscience inform the development of treatment for Anorexia Nervosa? Behav. Res. Ther. 62, 47-59. doi: 10.1016/j.brat.2014.07.007

Patel, S., and Cone, R. D. (2015). Neuroscience: a cellular basis for the munchies. Nature 519, 38-40. doi: 10.1038/nature14206

Pertwee, R. G. (2010). Receptors and channels targeted by synthetic cannabinoid receptor agonists and antagonists. Curr. Med. Chem. 17, 1360-1381. doi: $10.2174 / 092986710790980050$

Pertwee, R. G. (2014). Elevating endocannabinoid levels: pharmacological strategies and potential therapeutic applications. Proc. Nutr. Soc. 73, 96-105. doi: $10.1017 /$ S0029665113003649

Pinto, S., Roseberry, A. G., Liu, H., Diano, S., Shanabrough, M., Cai, X., et al. (2004). Rapid rewiring of arcuate nucleus feeding circuits by leptin. Science 304, 110-115. doi: 10.1126/science.1089459

Piomelli, D. (2003). The molecular logic of endocannabinoid signalling. Nat. Rev. Neurosci. 4, 873-884. doi: 10.1038/nrn1247

Rajaraman, G., Simcocks, A., Hryciw, D. H., Hutchinson, D. S., and Mcainch, A. J. (2016). G protein coupled receptor 18: a potential role for endocannabinoid signaling in metabolic dysfunction. Mol. Nutr. Food Res. 60, 92-102. doi: $10.1002 / \mathrm{mnfr} .201500449$

Reuter, S. E., and Martin, J. H. (2016). Pharmacokinetics of cannabis in cancer cachexia-anorexia syndrome. Clin. Pharmacokinet. 55, 807-812. doi: 10.1007/s40262-015-0363-2

Romanov, R. A., Zeisel, A., Bakker, J., Girach, F., Hellysaz, A., Tomer, R., et al. (2017). Molecular interrogation of hypothalamic organization reveals distinct dopamine neuronal subtypes. Nat. Neurosci. 20, 176-188. doi: 10.1038/nn.4462

Rouzer, C. A., and Marnett, L. J. (2011). Endocannabinoid oxygenation by cyclooxygenases, lipoxygenases, and cytochromes P450: cross-talk between the eicosanoid and endocannabinoid signaling pathways. Chem. Rev. 111, 5899-5921. doi: 10.1021/cr2002799

Savinainen, J. R., Saario, S. M., and Laitinen, J. T. (2012). The serine hydrolases MAGL, ABHD6 and ABHD12 as guardians of 2-arachidonoylglycerol signalling through cannabinoid receptors. Acta Physiol. 204, 267-276. doi: $10.1111 / j .1748-1716.2011 .02280 . x$

Scarlett, J. M., and Marks, D. L. (2005). The use of melanocortin antagonists in cachexia of chronic disease. Expert Opin. Investig. Drugs 14, 1233-1239. doi: $10.1517 / 13543784.14 .10 .1233$

Seeley, R. J., and Berridge, K. C. (2015). The hunger games. Cell 160, 805-806. doi: 10.1016/j.cell.2015.02.028

Shao, Z., Yin, J., Chapman, K., Grzemska, M., Clark, L., Wang, J., et al. (2016). High-resolution crystal structure of the human CB1 cannabinoid receptor. Nature 540, 602-606. doi: 10.1038/nature20613

Silvestri, C., and Di Marzo, V. (2013). The endocannabinoid system in energy homeostasis and the etiopathology of metabolic disorders. Cell Metab. 17, 475-490. doi: 10.1016/j.cmet.2013.03.001

Simiand, J., Keane, M., Keane, P. E., and Soubrie, P. (1998). SR 141716, a CB1 cannabinoid receptor antagonist, selectively reduces sweet food intake in marmoset. Behav. Pharmacol. 9, 179-181.

Soria-Gomez, E., Bellocchio, L., Reguero, L., Lepousez, G., Martin, C., Bendahmane, M., et al. (2014a). The endocannabinoid system controls food intake via olfactory processes. Nat. Neurosci. 17, 407-415. doi: 10.1038/nn.3647

Soria-Gomez, E., Massa, F., Bellocchio, L., Rueda-Orozco, P. E., Ciofi, P., Cota, D., et al. (2014b). Cannabinoid type-1 receptors in the paraventricular nucleus of the hypothalamus inhibit stimulated food intake. Neuroscience 263C, 46-53. doi: 10.1016/j.neuroscience.2014.01.005

Tam, J., Cinar, R., Liu, J., Godlewski, G., Wesley, D., Jourdan, T., et al. (2012). Peripheral cannabinoid-1 receptor inverse agonism reduces obesity by reversing leptin resistance. Cell Metab. 16, 167-179. doi: $10.1016 /$ j.cmet.2012.07.002

Thibault, K., Carrel, D., Bonnard, D., Gallatz, K., Simon, A., Biard, M., et al. (2013). Activation-dependent subcellular distribution patterns of CB1 cannabinoid receptors in the rat forebrain. Cereb. Cortex 23, 2581-2591. doi: 10.1093/cercor/bhs240

Urquhart, P., Nicolaou, A., and Woodward, D. F. (2015). Endocannabinoids and their oxygenation by cyclo-oxygenases, lipoxygenases and other oxygenases. Biochim. Biophys. Acta 1851, 366-376. doi: 10.1016/j.bbalip.2014. 12.015 
Vallee, M., Vitiello, S., Bellocchio, L., Hebert-Chatelain, E., Monlezun, S., Martin-Garcia, E., et al. (2014). Pregnenolone can protect the brain from cannabis intoxication. Science 343, 94-98. doi: 10.1126/science. 1243985

Varela, L., and Horvath, T. L. (2012). Leptin and insulin pathways in POMC and AgRP neurons that modulate energy balance and glucose homeostasis. EMBO Rep. 13, 1079-1086. doi: 10.1038/embor.2012.174

Verty, A. N., Boon, W. M., Mallet, P. E., Mcgregor, I. S., and Oldfield, B. J. (2009). Involvement of hypothalamic peptides in the anorectic action of the $\mathrm{CB}$ receptor antagonist rimonabant (SR 141716). Eur. J. Neurosci. 29, 2207-2216. doi: 10.1111/j.1460-9568.2009.06750.x

Vogt, M. C., and Bruning, J. C. (2013). CNS insulin signaling in the control of energy homeostasis and glucose metabolism - from embryo to old age. Trends Endocrinol. Metab. 24, 76-84. doi: 10.1016/j.tem.2012. 11.004

Volkow, N. D., Wang, G. J., and Baler, R. D. (2011). Reward, dopamine and the control of food intake: implications for obesity. Trends Cogn. Sci. 15, 37-46. doi: 10.1016/j.tics.2010.11.001

Walter, L., and Stella, N. (2004). Cannabinoids and neuroinflammation. Br. J. Pharmacol. 141, 775-785. doi: 10.1038/sj.bjp.0705667
Whiting, P. F., Wolff, R. F., Deshpande, S., Di Nisio, M., Duffy, S., Hernandez, A. V., et al. (2015). Cannabinoids for medical use: a systematic review and meta-analysis. JAMA 313, 2456-2473. doi: 10.1001/jama.2015.6358

Williams, C. M., and Kirkham, T. C. (1999). Anandamide induces overeating: mediation by central cannabinoid (CB1) receptors. Psychopharmacology 143, 315-317. doi: 10.1007/s002130050953

Zhang, X., and van den Pol, A. N. (2016). Hypothalamic arcuate nucleus tyrosine hydroxylase neurons play orexigenic role in energy homeostasis. Nat. Neurosci. 19, 1341-1347. doi: 10.1038/nn.4372

Conflict of Interest Statement: The author declares that the research was conducted in the absence of any commercial or financial relationships that could be construed as a potential conflict of interest.

Copyright (c) 2017 Koch. This is an open-access article distributed under the terms of the Creative Commons Attribution License (CC BY). The use, distribution or reproduction in other forums is permitted, provided the original author(s) or licensor are credited and that the original publication in this journal is cited, in accordance with accepted academic practice. No use, distribution or reproduction is permitted which does not comply with these terms. 